\title{
AABEn NA CRIAÇÃO, IMPLANTAÇÃO E DESENVOLVIMENTO DOS CONSELHOS DE ENFERMAGEM
}

\author{
THE PARTICIPATION OF THE BRAZILIANASSOCIATION OF NURSING \\ (ABEn) IN THE FOUNDATION, IMPLANTATIONAND DEVELOPMENT OF \\ NURSING BOARDS \\ LAABEN EN LACREACIÓN, IMPLANTACIÓN Y DESARROLLO DE LOS \\ CONSEJOS DE ENFERMERÍA
}

Maria Ivete Ribeiro de Oliveira'

Neide Maria Freire Ferraz²

\begin{abstract}
RESUMO: A Associação Brasileira de Enfermagem - ABEn "75" Anos de existência, berço de outras organizações profissionais e núcleo propulsor do desenvolvimento da profissão de enfermagem no país. A criação, implantação e desenvolvimento dos Conselhos de Enfermagem como empreendimento de destaque da ABEn, 28 anos de luta para a aprovação da Lei n5.905 de 12 de julho de 1973 que criou os Conselhos de Enfermagem, Implantação do Conselho Federal de Enfermagem- COFEN e dos CORENs sob a liderança da ABEn. Participação da ABEn no processo de desenvolvimento dos Conselhos Federal e Regionais de Enfermagem. Situação atual do relacionamento da $\mathrm{ABEn}$ com outros entidades de classe e em particular com os Conselhos de Enfermagem.
\end{abstract}

\section{PALAVRAS-CHAVE: ABEn, COFEN, história da enfermagem}

Os enfermeiros brasileiros estão comemorando no corrente exercício os "75 anos" de existência de sua mais antiga entidade de classe. A ABEn, berço de outras organizações profissionais, com uma bonita trajetória, tem sido, sem a menor dúvida, o núcleo propulsor do desenvolvimento da profissão de enfermagem no pais, ao longo dessas décadas, confundindo a sua história com a própria história profissional. Podemos dizer que essa história tem sido construida com tenacidade e dedicação nesses sucessivos periodos, guardando cada qual características particulares. A conformação tomada em cada qual dessas fases se deve tanto à marca que foi impressa por aqueles que integraram a Entidade, sobretudo seus dirigentes na condução do seu destino, visando o atendimento das exigências fundamentais especificas, quanto às características econômicas, social, moral, politico-ideológica predominantes na sociedade. Daí a importância da celebração das datas históricas na vida das instituições. É a oportunidade não apenas para rememorar e apreciar o trabalho daqueles que, no passado, buscaram adotar soluções que lhes pareceram adequadas para os problemas encontrados, quanto para os que hoje têm a responsabilidade de conduzir a organização, direcionando suas ações de acordo com as exigências de seu tempo, respeitando o legado recebido.

Acompanhando o registro histórico das muitas lutas encetadas pela ABEn, verifica-se que o caminho percorrido nem sempre foi fácil em virtude dos numerosos obstáculos encontrados ao longo dessa trajetória, talvez como decorrente da própria natureza da prática profissional o que, certamente, exigiu muito envolvimento pessoal dos protagonistas, na consecução dos

\footnotetext{
Enfermeira, professor Emérito da Universidade Federal da Bahia.

2 Enfermeira, professora aposentada da Universidade Federal de Pernambuco, membro do Conselho Fiscal Nacional da ABEn.
} 
objetivos e metas traçados.

Dentre os vários embates empreendidos pela $A B E n$, merece destacar aqueles que dizem respeito à criação, implantação e desenvolvimento dos Conselhos de Enfermagem em moldes semelhantes àqueles congêneres já funcionando em outras áreas profissionais, guardadas, naturalmente, as características do exercício da prática profissional

\section{A CRIAÇÃo}

Os estudiosos da história da enfermagem no pais creditam a Zaíra Cintra Vidal, então ABED, a primeira iniciativa de entrar no Ministério de Educação e Saúde com projeto de Lei, nos idos de 45, visando à criação de um Conselho Nacional de Enfermagem. Seria na concepção original, "um órgão para estudar e fiscalizar todos os assuntos concernentes ao ensino e à prática da Enfermagem".

Desde então o assunto "Conselho" passou a dominar o interesse da classe e muitos estudos foram feitos, inclusive com auxílio de especialistas. Naquela oportunidade, porém, não havia mais que umas poucas dezenas de enfermeiras "diplomadas". No Ministério do Trabalho, a enfermagem era representada pelos chamados "enfermeiros" muito embora não passassem de "práticos de enfermagem", sem formação específica. Esses eram também os representantes em outros órgãos federais. O Ensino da enfermagem no país, sequer estava regulamentado, 0 que somente viria ocorrer com a Lei 775/49 e seu regulamento.

A partir desse marco, os congressos de Enfermagem passaram a estudar o assunto com mais afinco. Conforme Carvalho (1976) destaca em seu Documentário que os anos de 19521953 foram de intensa atividade visando a regulamentação do exercício da prática de enfermagem. Até mesmo um projeto fora elaborado e enviado ao Ministério da Educação, projeto esse transformado depois na Lei $n^{\circ} 2.604 / 55$.

Concomitantemente, a ABEn continuou insistindo na criação de um órgão com a participação de enfermeiras no controle da profissão o que foi feito com a criação de uma Seção de Enfermagem no Serviço no Serviço Nacional da Fiscalização da Medicina (SNFM) ligado ao Ministério da Educação.

\section{AIMPLANTAÇÃO}

Finalmente, foram criados os Conselhos de Enfermagem pela Lei $n^{\circ} 5.905$ de 12 de julho de 1973. A classe estava suficientemente amadurecida para assumir essa grande responsabilidade e assim o fez com entusiasmo e brilho sob liderança da ABEn. Cumpria de imediato seguir o disposto no artigo 21 do citado diploma legal que determinava a composição do primeiro Conselho Federal de Enfermagem. Este deveria ser feito por ato do Ministro do Trabalho e Previdência Social. Em obediência a este dispositivo, a ABEn, após receber indicação de suas seções estaduais, enviou ao Ministro Arnaldo da Costa Prieto, em 12 de novembro de 1973, lista com 54 nomes para escolha de nove conselheiras efetivas e igual número de suplentes.

Conforme consta do primeiro relatório do Plenário do COFEN (1986), a portaria MTB n³.059, de 5 de março de 1975, designou nove enfermeiras na condição de membros efetivos e igual número de suplentes.

A primeira reunião dos membros do COFEN foi convocada pela presidente da ABEn e efetuada em 23 de abril no Ministério do Trabalho, tendo sido presidida pela enfermeira Maria da Graça Corte Imperial e secretariada por Isaura Lopes de Godoy, respectivamente presidente e secretária da ABEn, reunião essa destinada a eleger a Diretoria do COFEN.

Foram eleitas para a Diretoria: Presidente Maria Rosa Sousa Pinheiro, Vice-presidente Amália Correia de Carvalho, Secretária Maria Elena da Siva Nèry, $1^{\text {a }}$ Tesoureira Raimunda da Silva Beker, $2^{\text {a }}$ Secretária Vani Chika Faraon, $2^{\text {a }}$ Tesoureira Judith Feitosa de Carvalho. 
No dia imediato os membros do COFEN já estavam reunidos elaborando um cronograma de atividades a serem desenvolvidas nos primeiros doze meses. Dentre essas, destaca-se a elaboração de nove ante-projetos de Lei que deveriam substituir a Lei 2.604/55, além da estimativa do número de enfermeiros em atividade no Distrito Federal e nos estados, a ser conseguido junto às seções da ABEn e, a partir desses dados fixar o, o número de membros dos Conselhos Regionais (CORENs). Também a União Nacional de Auxiliares de Enfermagem (UNAE) contribuiu, fazendo a estimativa de auxiliares de enfermagem.

O COFEN preocupou-se, logo de início, com a obtenção de recursos financeiros, tendo solicitado ao Ministério do Trabalho. Em face, porém, das dificuldades surgidas para a liberação do numerário requerido e, tendo em vista as efetivas necessidades enfrentadas pelo órgão recém criado, mais uma vez a ABEn veio em ajuda, fazendo o empréstimo dos recursos solicitados, facilitando assim o início das atividades, conforme programadas. O problema do espaço físico para a instalação dos trabalhos foi resolvido com a cooperação das escolas de enfermagem e das seções da ABEn. E assim, o competente Plenário COFEN foi resolvendo os problemas iniciais, contando sempre com o entusiástico apoio das instituições de enfermagem.

\section{CONSELHOS REGIONAIS DE ENFERMAGEM}

Para a instalação dos Conselhos Regionais de Enfermagem(CORENs), e a promoção das primeiras eleições, o Grupo de Trabalho, constituido pelo COFEN para resolver as questões iniciais, obteve assessoria dos Conselhos Federal de Odontologia e Regional de Farmácia que sugeriram a constituição de Juntas Especiais sediadas nas capitais, onde seriam instalados os CORENs, contando, para tanto, com o apoio das seções da ABEn. Essas Juntas estavam incumbidas de receber a documentação do pessoal de enfermagem, para efeito de habilitação à inscrição e realização das eleições. Havia que resolver o problema financeiro para despesas iniciais mais imediatas, o que foi feito graças a contribuição dos próprios membros das Juntas, até que fosse possivel arrecadar os primeiros emolumentos os quais foram recolhidos através de rede bancária. Conforme o Relatório, já anteriormente referido, seguiram-se outras providências a serem tomadas, a curto prazo, decorrentes da determinação de convocar a Assembléia dos Delegados Regionais para eleger os membros do Conselho Federal noventa dias, antes do término de seu mandato. A instalação das Juntas Especiais e a orientação de seus membros constituiam as primeiras daquelas providências. Contribuiu decisivamente, para a consecução do objetivo, a realização do XXVII Congresso Brasileiro de Enfermagem, da ABEn, no mesmo local e na mesma data em que o Plenário marcara a reunião em que vieram a ser aprovados o plano de ação e os atos normativos.

A programação do Congresso acima mencionado incluía a realização de pequenos cursos intensivos entre esses o de legislação de Enfermagem, a cargo da presidente do COFEN, para o qual acorreram, além das presidentes das seções da ABEn, um grande número de enfermeiros.

Montada a estrutura provisória dos CORENs, foi possivel a realização das primeiras eleições nos Conselhos. É importante destacar as palavras da presidente do COFEN, contidas no Relatório já mencionado: "é digna de menção especial a qualidade do trabalho desenvolvido, não só pelos membros das Juntas e pelas presidentes das seções da ABEn, como, também, pela presidente da UNAE e dos voluntários: enfermeiros, auxiliares de enfermagem e outros.

\section{O DESENVOLVIMENTO}

Instalados os Conselhos Federal e Regionais, cumpria consolidar essas estruturas para que as atividades fins pudessem ser desenvolvidas. Mais uma vez a ABEn e sua seções participaram ativamente desse processo. Destaque-se para isso a discussão em todo o país do novo projeto de Lei do Exercício Profissional, que viria substituir a já obsoleta legislação 
conhecida como ${ }^{\circ} 2.604 / 55$. O ante-projeto proposto pelo COFEN, transformado em projeto de Lein ${ }^{\circ} 3427 / 80$, foi aprovado integralmente pela Câmara dos Deputados em 12 de maio de 1982. No Senado, tomou o $n^{\circ} 60 / 82$, tendo sido aprovado no Plenário daquela Casa, transformando-se na Lei $n^{0} 7498 / 86$.

Paralelamente a esse esforço, o COFEN e a ABEn mantiveram seguidos contatos com o Ministério da Educação e o então Conselho Federal de Educação para esclarecerem as disposições relativas ao Magistério da Enfermagem, bem como os Ministérios da Saúde, do Trabalho e o Departamento da Administração do Serviço Público-DASP, tudo para discutir e esclarecer pontos em controvérsia.

Ademais, cumpria discutir de modo o mais abrangente possivel o Código de Ética, proposto pelo COFEN. Os seminários promovidos conjuntamente pelo COFEN e a ABEn, sempre por ocasião dos Congressos de Enfermagem, eram oportunidades para divulgação do trabalho dos Conselhos, sobretudo dos complexos problemas envolvidos na fiscalização da prática profissional. Foi a partir desses encontros que foram elaboradas diversas Resoluções e Manuais, concernentes ao tema em questão. Outros trabalhos foram realizados em parceria com o COFEN como a publicação do Estudo do Exercício de Enfermagem nas Instituições de Saúde do Brasil-19821983. O volume I estudou a "Força de Trabalho de Enfermagem" e o volume 2 "Enfermagem no Contexto Institucional". No volume I, procurou-se identificar a composição da força de trabalho ocupada em 1983, incluindo número, distribuições, nivel de escolaridade, formação profissional e ocupacional, funções desempenhadas pelas diferentes categorias de pessoal e forma como se processava a inserção no mercado de trabalho, além dos problemas que afetavam o exercício da profissão em cada nível pesquisado e, no volume 2 , buscou-se conhecer o ponto de vista das administrações das entidades e estabelecimentos tendo sido apontados, em ambos, as mudanças previstas ou esperadas em decorrência da reorientação do sistema de prestação dos serviços de saúde à população brasileira. Este estudo resultou de um convênio COFEN/ ABEn com o apoio financeiro do COFEN e de outras entidades como o INAMPS, o CNPq e colaboração do Ministério da Saúde e de várias universidades federais e estaduais.

Mais uma manifestação de ação conjunta das duas entidades já mencionadas foi a publicação do trabalho Direito à Saúde e Direito à Assistência de Enfermagem-Contribuição do COFEN e da ABEn (COFEN/ABEn, 1986) para o debate da VIII Conferência Nacional de Saúde, publicado em Brasilia em março de 1986,considerado como um posicionamento da enfermagem brasileira naquele encontro nacional.

A partir do final daquela década e a seguinte, houve aumento da demanda por serviços de saúde e, conseqüentemente, isso se refletiu no crescimento vegetativo do número de inscritos nos Conselhos de Enfermagem. Verificou-se, entretanto, um progressivo esgarçamento das relações entre as duas entidades (COFEN e ABEn), de tal sorte a inviabilizar qualquer trabalho de parceria, com vistas sempre ao encaminhamento conjunto dos problemas do interesse da profissão tão bem equacionados nos estudos acima mencionados. Diga-se a propósito, da importância que teria o esforço conjunto dessas entidades para estímulo e apoio aos núcleos de pesquisa que os cursos de pós-graduação em enfermagem vêm desenvolvendo com tanta dedicação e competência, mas com dificuldades de natureza financeira para custeio dos projetos. Ademais, as questões que envolvem o ensino de enfermagem, em todos os niveis, estão a merecer um trabalho mais articulado das entidades referidas. Vale ressaltar, também, uma especial atenção às demandas que os exercentes da enfermagem continuam fazendo com referência aos problemas da prática profissional e que exigem, portanto, um efetivo posicionamento das entidades de enfermagem. Afinal, a profissão e os profissionais estão acima dos eventuais interesses pessoais ou de cada qual dessas entidades que existem para atender exclusivamente aos que tornam possivel suas existências.

AABEn, como entidade de caráter científico, social, político e cultural; o COFEN e os CORENs como órgãos disciplinadores e o Sindicato como órgão defensor dos direitos trabalhistas 
dos profissionais da área, constituem as três entidades que, em princípio, devem se completar num trabalho articulado para fortalecer o crescimento da enfermagem brasileira e das instituições de saúde no país. Por outro lado, para que essas entidades alcancem o máximo de sua eficiência, é importante contar com prestígio e o apoio dos profissionais de enfermagem.

Cabe às gerações futuras a responsabilidade de preservar o legado recebido para continuar na construção de entidades fortes e comprometidas com o desenvolvimento de uma sociedade brasileira menos desigual e serviços de saúde que atendam aos reclames da população.

ABSTRACT: The Brazilian Association of Nursing (ABEn) was founded in 1926. The association has been the source for the creation of new professional organizations and the motivator of the development of the nursing profession in the country. The creation, implantation and development of the nursing boards are important achievements of ABEn. Twenty-eight years of struggle to approve the law number 5.905 of 12 July 1973, which created the nursing boards. Implantation of the Federal Board of Nursing (COFEn) and CORENS done under the leadership of ABEn. ABEn's participation in the development of the federal and regional boards of nursing. Current situation of the relationship between $A B E n$, syndicates, and nursing boards.

KEYWORDS: ABEn, COFEn, history of nursing

RESUMEN: La Asociación Brasileña de Enfermería -ABEn en sus 75años" de existencia, cuna de otras organizaciones profesionales y núcleo propulsor del desarrollo de la profesión de enfermería en el país. Sus Consejos de Enfermería como una empresa de proyección de la ABEn, los 28años de lucha que trajeron como resultado la ley de n5.905 del 12 de julio de 1973 que creó los Consejos de Enfermería. La implantación del "Conselho Federal de Enfermagem-COFEn" y de los CORENS bajo el liderazgo de la ABEn. La participación de ABEn en el proceso de desarrollo de los Consejos Federal y Regionales de Enfermería y su situação actual con otras entidades de clase y en particular con los Consejos de Enfermería.

PALABRAS CLAVE: ABEn, COFEN, historia de la enfermeria

\section{REFERÊNCIAS BIBLIOGRÁFICAS}

CARVALHO, A.C. Associação Brasileira de Enfermagem-1926-1976-Documentário. Rio de Janeiro: ABEn,1976.

COFEN. Enfermagem-Criação e instalação da sua autarquia profissional-Gestão 23 de abril de 1975 a 22 de abril de 1986. Mimeogr.

COFEN/ABEn. Direito à Saúde e Direito à Assistência de Enfermagem. Brasília: COFEN/ABEn, 1986. Mimeogr. 